\title{
PENGARUH PERSEPSI WAJIB PAJAK DAN PREFERENSI RISIKO TERHADAP KEPATUHAN WAJIB PAJAK
}

\author{
Wiwit Irawati ${ }^{1}$, Arum Kumala Sari ${ }^{2}$ \\ Dosen Program Studi Akuntansi, Universitas Pamulang
}

email: dosen00869@unpam.ac.id

\begin{abstract}
This study aims to examine the effect of Taxpayer Perception and Risk Preference on Taxpayer Compliance. Taxpayer compliance is a very important thing and is needed so that the state revenue in the tax sector is maximized. This research was conducted using convenience sampling with a sample of 100 respondents from individual taxpayers at the Jakarta KPP Kebayoran Baru Tiga. The data used are primary data through a questionnaire containing respondents' answers. The data analysis used in this study is multiple linear regression analysis, which includes the Determination Coefficient Test, T Test and $F$ Test. Before the hypothesis test, the collected data will be through a data quality test consisting of Normality Test, Multicollinearity Test and Heteroscedasticity Test. The results of this study indicate that Taxpayer Perception has a positive and significant effect on Taxpayer Compliance. While Risk Preference does not affect Taxpayer Compliance. But simultaneously Taxpayer Perception and Risk Preference have a significant effect on Taxpayer Compliance
\end{abstract}

Keywords: Taxpayer Perception, Risk Preference, Taxpayer Compliance.

\section{PENDAHULUAN}

\subsection{Latar Belakang Penelitian}

Pajak merupakan sumber penerimaan negara yang mencerminkan kegotong royongan masyarakat dalam membiayai negara. Penerimaan negara saat ini dapat berasal dari penerimaan dari pajak dan penerimaan bukan pajak. Dari sektor pajak diharapkan penerimaan dapat meningkat melihat dari semakin bertambah besarnya jumlah wajib pajak baik Wajib Pajak Orang Pribadi maupun Wajib Pajak Badan.

Di Indonesia pajak penghasilan dipungut berdasarkan sistem self assessment. Sistem self assessment memberikan kepercayaan penuh kepada wajib pajak untuk menghitung memperhitungkan, menyetor, dan melaporkan seluruh pajak yang menjadi kewajibannya. Pada praktiknya sistem self assessment sulit dijalankan dan sering disalah gunakan seehingga bertentangan dengan harapan pemerintah agar sistem tersebut dapat memaksimalkan penerimaan negara dari sektor pajak. Hal ini juga terkait dengan cara pandang Wajib Pajak dalam menyikapi pembayaran pajaknya. Di mana setiap Wajib Pajak memiliki persepsi masingmasing terhadap pajak. Menurut Luthas dalam (Dewi, 2011), "Persepsi dibentuk oleh dua faktor, yang pertama adalah faktor internal yaitu berhubungan dengan karakteristik dari individu dan yang kedua adalah faktor eksternal yaitu berhubungan dengan lingkungan dan situasi.“"

Kepatuhan perpajakan adalah suatu tindakan Wajib Pajak dalam memenuhi hak dan kewajiban perpajakan yang berlaku dalam suatu negara. Dapat dilihat dari patuh atau tidaknya seorang Wajib Pajak dalam mendaftarkan dirinya, menyetorkan kembali surat pemberitahuan pajak, kepatuhan Wajib Pajak dalam perhitungan dan pembayaran pajak terutangnya.

Dalam menjalankan kewajiban perpajakannya, Wajib Pajak juga dihadapkan pada risikorisiko yang harus dipertimbangkan dalam membayar pajak. Risiko yang dipertimbangkan 
antara lain risiko kesehatan, risiko keuangan, risiko sosial, risiko karir wajib pajak dan risiko keselamatan.

\subsection{Tujuan Penelitian}

1. Untuk menguji dan memberi bukti empiris Persepsi Wajib Pajak berpengaruh terhadap Kepatuhan Wajib Pajak

Untuk menguji dan memberi bukti empiris Preferensi Risiko dapat memoderasi hubungan antara Persepsi Wajib Pajak berpengaruh terhadap Kepatuhan Wajib Pajak.

\section{TINJAUAN PUSTAKA}

\subsection{Landasan Teori}

\subsubsection{Teori Keagenan (Agency Theory)}

Teori keagenan pertama kali dikemukakan oleh Jansen dan Meckling, (1976). Teori ini muncul karena adanya hubungan antara principal dan agent. Teori agensi mengasumsikan bahwa semua individu bertindak atas kepentingan mereka sendiri. Pemegang saham sebagai principal diasumsikan hanya tertarik kepada hasil keuangan atau investasi mereka yang bertambah di dalam perusahaan sedangkan agen diasumsikan cenderung berkeinginan untuk menerima kepuasan berupa kompensasi keuangan maupun fasilitas lainnya yang lebih besar, (Pertiwi, 2015). Pada penelitian ini perbedaan kepentingan yang terjadi adalah antara pihak pemerintah atau fiskus dengan Wajib Pajak. Di mana fiskus sebagai pemungut pajak dan wajib pajak memiliki kepentingan yang berbeda. Wajib pajak berusaha untuk meminimalkan atau bahkan menghindari pembayaran pajak dengan anggapan bahwa pajak tersebut sebagai beban yang dapat mengurangi kemampuan ekonomis. Oleh karena itu, wajib pajak melakukan berbagai cara untuk menghindari dan mengurangi jumlah pembayaran pajaknya. Hal ini, tentu dapat mengurangi tingkat kepatuhan wajib pajak.

\subsubsection{Teori Prospek ( Prospect Theory )}

Teori prospek merupakan teori yang dikembangkan oleh Kahneman dan Tversky (1979). Kahneman dan Tversky (1979) ,'Perilaku manusia kadang aneh dan kontradiktif dalam mengambil suatu keputusan, ada perilaku yang cenderung menyukai tantangan atau risiko sebagai risk aversion behavior dan ada juga yang cenderung menghindari risiko yakni risk seeking behavior."

Hubungan antara penelitian ini dengan teori prospek dimana teori prospek menjelaskan mengenai preferensi risiko dapat mempengaruhi kepatuhan wajib pajak. Apabila seorang wajib pajak memiliki risiko yang tinggi maka wajib pajak tersebut belum tentu tidak akan membayar kewajiban pajaknya. Sedangkan apabila wajib pajak itu memiliki sifat risk seeking maka walaupun wajib pajak memiliki risiko tinggi, tidak akan mempengaruhi wajib pajak untuk tetap membayar pajak, sedangkan wajib pajak yang memiliki sifat risk aversion maka walaupun wajib pajak memiliki risiko yang rendah maka wajib pajak tetap akan menghindari pelaksanaan kewajiban perpajakannya (Aryobimo, 2012).

\subsection{Persepsi Wajib Pajak}

Thoha, (2007:141) dalam Mangumban (2015), " Persepsi pada hakikatnya adalah proses kognitif yang dialami oleh setiap orang dalam memahami informasi tentang lingkungannya, baik lewat penglihatan, penghayatan, perasaan dan penciuman".

Dengan persepsi Wajib Pajak yang baik terhadap kewajiban perpajakannya maka dengan sendirinya Wajib Pajak akan patuh. Sebaliknya jika persepsi Wajib Pajak buruk terhadap kewajiban perpajakannya maka kemungkinan besar Wajib Pajak tidak akan patuh. "Perilaku sesorang akan sangat dipengaruhi oleh persepsi orang tersebut", (Gibson dalam Mangumban, (2015:13).

Pemerintah berupaya membenahi sarana dan prasarana perpajakan untuk dapat memberikan pelayanan lebih baik lagi. Pemerintah sangat berkepentingan untuk menampilkan citra yang baik dan bersahabat terhadap Wajib Pajak sehingga mereka dapat patuh melaksanakan hak dan kewajiban perpajakannya. 


\subsection{Preferensi Risiko}

Sitkin dan Pablo (1992) menyatakan bahwa, "preferensi risiko merupakan salah satu karakteristik seseorang yang akan mempengaruhi prilakunya." Sedangkan Torgler (2003) dalam Syamsudin (2014) menyampaikan bahwa,"Keputusan Wajib Pajak individu dapat dipengaruhi oleh sikap mereka terhadap risiko."

Teori Prospek menjelaskan bahwa Wajib Pajak akan memilih sikap yang memiliki prospek lebih baik untuk mereka. "Ketika Wajib Pajak beranggapan tingkat risiko yang dihadapi adalah tinggi maka tingkat kepatuhan wajib pajak akan rendah. Dan sebaliknya jika risiko rendah, maka tingkat kepatuhan Wajib Pajak akan tinggi." Ismawati (2017). Preferensi risiko sendiri terdiri dari : Risiko keuangan, Risiko Sosial, Risiko Pekerjaan/ karir, Risiko Keselamatan Kerja dan Risiko Kesehatan.

\subsection{Kepatuhan Wajib Pajak}

Dalam Kamus Besar Indonesia bahwa, "Kepatuhan adalah tunduk atau patuh terhadap ajaran atau peraturan". Kepatuhan dalam perpajakan dapat diartikan ketaatan, tunduk, dan patuh pada ajaran serta melaksanakan ketentuan perpajakan. Wajib Pajak yang patuh adalah Wajib Pajak yang taat dan mematuhi serta melaksanakan kewajiban perpajakannya sesuai dengan ketentuan peraturan perundang - undangan perpajakan.

Direktorat Jenderal Pajak menyatakan bahwa Wajib Pajak yang patuh adalah Wajib Pajak yang sudah memenuhi kriteria tertentu. Berdasarkan Peraturan Menteri Keuangan Republik Indonesia No.74/PMK.03/2012 Pasal 2, "Untuk dapat ditetapkan sebagai Wajib Pajak Dengan Kriteria Tertentu, Wajib Pajak harus memenuhi persyaratan sebagai berikut : (1)Tepat waktu dalam menyampaikan Surat Pemberitahuan; (2) Tidak mempunyai tunggakan pajak untuk semua jenis pajak, kecuali tunggakan pajak yang telah memperoleh izin mengangsur atau menunda pembayaran pajak; (3) Laporan Keuangan diaudit oleh Akuntan Publik atau Lembaga Pengawasan Keuangan Pemerintah dengan pendapat Wajar Tanpa Pengecualian selama tiga tahun berturut - turut: dan (4) Tidak pernah dipidana karena melakukan tindak pidana dibidang perpajakan berdasarkan putusan pengadilan yang telah mempunyai kekuatan hukum tetap dalam jangka waktu lima tahun terakhir."

\section{METODE}

Rancangan penelitian ini menggunakan pendekatan kuantitatif, jenis data primer dengan cara menyebar kuesioner kepada responden yang berasal dari populasi Wajib Pajak Orang Pribadi pada KPP Pratama Jakarta Kebayoran Baru tiga yang tercatat pada tahun 2017 sebanyak 14.615 Wajib Pajak. Sempel yang akan digunakan dipilih dengan teknik convinience sampling dengan menggunakan rumus Slovin yang menghasilkan sebanyak 100 responden.

Sebelumnya instrumen penelitian akan diuji menggunakan Uji Validitas dan Reliabilitas, selanjutnya data yang terkumpul akan diuji menggunakan uji Asumsi Klasik yang terdiri dari Uji Normalitas, Uji Multikolinieritas dan Uji Heteroskedastisitas. Sesudahnya uji hipotesis dengan menggunakan analisis regresi linier berganda, yang terdiri dari Uji Koefisien Determinasi, Uji T dan Uji F.

\section{HASIL DAN PEMBAHASAN \\ 4.1 Statistik Deskriptif}

Hasil Statistik deskriptif mencakup nilai maksimal, minimal, standar deviasi, dan ratarata yang sesuai dengan jawaban 100 responden penelitian. 
Tabel 4.1

Statistik Deskriptif

\begin{tabular}{|l|r|r|r|r|r|} 
& N & Minimum & Maximum & Mean & Std. Deviation \\
\hline Persepsi Wajib Pajak & 100 & 72 & 125 & 101,25 & 7,953 \\
Preferensi Risiko & 100 & 5 & 25 & 15,94 & 3,348 \\
Kepatuhan Wajib Pajak & 100 & 25 & 50 & 41,31 & 3,894 \\
Valid N (listwise) & 100 & & & & \\
& & & & & \\
\hline
\end{tabular}

Berdasarkan tabel 4.1, dapat dilihat bahwa nilai rata - rata dari Persepsi WajibPajak adalah sebesar 101,25 dengan standar deviasi 7,953. Serta nilai minimum sebesar 72 dan nilai maximum 125. Nilai rata - rata yang dimiliki Preferensi Risiko adalah sebesar 15,94 dengan standar deviasi 3,348, nilai minimum sebesar 5 dan nilai maximum 25. Nilai rata-rata yang dimiliki Kepatuhan Wajib Pajak adalah sebesar 41,31 dengan nilai deviasi 3,894, nilai minimum sebesar 25 dan nilai maximum 50.

\subsection{Uji Kualitas Instrument}

\subsubsection{Uji Validitas}

Tabel 4.2

Uji Validitas Persepsi Wajib Pajak

\begin{tabular}{|c|c|c|c|c|}
\hline No & Keterangan & r Hitung & r Tabel & Keterangan \\
\hline 1 & PWP-1 & 0,335 & 0,1986 & Valid \\
\hline 2 & PWP-2 & 0,373 & 0,1986 & Valid \\
\hline 3 & PWP-3 & 0,549 & 0,1986 & Valid \\
\hline 4 & PWP-4 & 0,501 & 0,1986 & Valid \\
\hline 5 & PWP-5 & 0,364 & 0,1986 & Valid \\
\hline 6 & PWP-6 & 0,496 & 0,1986 & Valid \\
\hline 7 & PWP-7 & 0,480 & 0,1986 & Valid \\
\hline 8 & PWP-8 & 0,580 & 0,1986 & Valid \\
\hline 9 & PWP-9 & 0,577 & 0,1986 & Valid \\
\hline 10 & PWP-10 & 0,461 & 0,1986 & Valid \\
\hline 11 & PWP-11 & 0,605 & 0,1986 & Valid \\
\hline 12 & PWP-12 & 0,612 & 0,1986 & Valid \\
\hline 13 & PWP-13 & 0,552 & 0,1986 & Valid \\
\hline 14 & PWP-14 & 0,713 & 0,1986 & Valid \\
\hline 15 & PWP-15 & 0,607 & 0,1986 & Valid \\
\hline 16 & PWP-16 & 0,670 & 0,1986 & Valid \\
\hline 17 & PWP-17 & 0,617 & 0,1986 & Valid \\
\hline
\end{tabular}




\begin{tabular}{|c|c|c|c|c|}
\hline 18 & PWP-18 & 0,564 & 0,1986 & Valid \\
\hline 19 & PWP-19 & 0,575 & 0,1986 & Valid \\
\hline 20 & PWP-20 & 0,708 & 0,1986 & Valid \\
\hline 21 & PWP-21 & 0,725 & 0,1986 & Valid \\
\hline 22 & PWP-22 & 0,649 & 0,1986 & Valid \\
\hline 23 & PWP-23 & 0,618 & 0,1986 & Valid \\
\hline 24 & PWP-24 & 0,676 & 0,1986 & Valid \\
\hline 25 & PWP-25 & 0,423 & 0,1986 & Valid \\
\hline
\end{tabular}

Tabel 4.3

Uji Validitas Preferensi Risiko

\begin{tabular}{|c|c|c|c|c|}
\hline No & Keterangan & r Hitung & r Tabel & keterangan \\
\hline 1 & PR-1 & 0,756 & 0,1986 & Valid \\
\hline 2 & PR-2 & 0.821 & 0,1986 & Valid \\
\hline 3 & PR-3 & 0,858 & 0,1986 & Valid \\
\hline 4 & PR-4 & 0,818 & 0,1986 & Valid \\
\hline 5 & PR-5 & 0,736 & 0,1986 & Valid \\
\hline
\end{tabular}

Tabel 4.4

Uji Validitas Kepatuhan Wajib Pajak

\begin{tabular}{|c|c|c|c|c|}
\hline No & Keterangan & r Hitung & r Tabel & keterangan \\
\hline 1 & KWP-1 & 0,210 & 0,1986 & Valid \\
\hline 2 & KWP-2 & 0,456 & 0,1986 & Valid \\
\hline 3 & KWP-3 & 0,793 & 0,1986 & Valid \\
\hline 4 & KWP-4 & 0,743 & 0,1986 & Valid \\
\hline 5 & KWP-5 & 0,818 & 0,1986 & Valid \\
\hline 6 & KWP-6 & 0,761 & 0,1986 & Valid \\
\hline 7 & KWP-7 & 0,766 & 0,1986 & Valid \\
\hline 8 & KWP-8 & 0,682 & 0,1986 & Valid \\
\hline 9 & KWP-9 & 0,732 & 0,1986 & Valid \\
\hline 10 & KWP-10 & 0,833 & 0,1986 & \\
\hline \hline
\end{tabular}


Berdasarkan tabel 4.2, 4.3 dan 4.4, hasil pengujian validitas menunjukan bahwa semua pertanyaan yang berhubungan dengan persepsi wajib pajak, kepatuhan wajib pajak dan preferensi risiko dapat dikatakan valid, dikarenakan setiap butir pertanyaan memilki nilai $r$ hitung lebih besar dr $\mathrm{r}$ tabel.

\subsubsection{Uji Reliabilitas}

Tabel 4.5

Reliabilitas Persepsi Wajib Pajak

\begin{tabular}{|r|r|}
\hline Cronbach's Alpha & N of Items \\
\hline, 908 & 25 \\
\hline
\end{tabular}

Tabel 4.6

Reliabilitas Preferensi Risiko

\begin{tabular}{|r|r|}
\hline Cronbach's Alpha & N of Items \\
\hline, 856 & 5 \\
\hline
\end{tabular}

Tabel 4.7

Reliabilitas Kepatuhan Wajib Pajak

\begin{tabular}{|r|r|}
\hline Cronbach's Alpha & N of Items \\
\hline, 87 & 10 \\
\hline
\end{tabular}

Hasil Uji reliabilitas menghasilkan nilai Cronbach's Alpha di atas 0,70 maka kuesioner tersebut dapat dikatakan handal atau reliable dan dapat digunakan untuk penelitian.

\subsection{Uji Asumsi Klasik}

\subsubsection{Uji normalitas}

Tabel 4.8

Hasil Uji Normalitas

\begin{tabular}{|c|c|c|}
\hline & & $\begin{array}{l}\text { Unstandardized } \\
\text { Residual }\end{array}$ \\
\hline \multicolumn{2}{|l|}{$\mathrm{N}$} & 100 \\
\hline Normal & Mean & ,0000000 \\
\hline \multicolumn{3}{|l|}{ Parameters $^{\mathrm{a}, \mathrm{b}}$} \\
\hline & Std. Deviation & 2,94757167 \\
\hline Most Extreme & Absolute & ,071 \\
\hline \multicolumn{3}{|l|}{ Differences } \\
\hline & Positive & 071 \\
\hline & Negative &,- 045 \\
\hline \multicolumn{2}{|c|}{ Kolmogorov-Smirnov Z } & ,707 \\
\hline \multicolumn{2}{|c|}{ Asymp. Sig. (2-tailed) } & ,700 \\
\hline
\end{tabular}


Kolmogorov smirnov test dengan hasil dari tabel 4.8 diketahui nilai signifikan (Asymp. Sig 2- tailed ) sebesar 0,700 , artinya nilai tersebut lebih tinggi dibandingkan dengan nilai signifikan $0,05(0,700>0,05)$ maka nilai residual tersebut telah terdistribusi normal.

\subsubsection{Uji Multikolonieritas}

Tabel 4.9

Uji Multikolinieritas

\begin{tabular}{|c|c|c|}
\hline \multirow{2}{*}{ Model } & \multicolumn{2}{|c|}{ Collinearity Statistics } \\
\hline & Tolerance & VIF \\
\hline $\begin{array}{ll}1 & \text { (Constant) } \\
& \text { Persepsi Wajib Pajak } \\
& \text { Preferensi Risiko }\end{array}$ & $\begin{array}{l}9966 \\
\text { 996 }\end{array}$ & $\begin{array}{l}1,004 \\
1,004\end{array}$ \\
\hline
\end{tabular}

Hasil uji multikolinieritas menunjukan bahwa nilai tolerance semua variabel independen dan moderating berada diatas 0,10 dan nilai Variance Inflation Factor (VIF) kurang dari 10, sehingga dapat disimpulkan bahwa tidak terjadi gejala multikolonieritas.

\subsubsection{Uji Heteroskedastisitas}

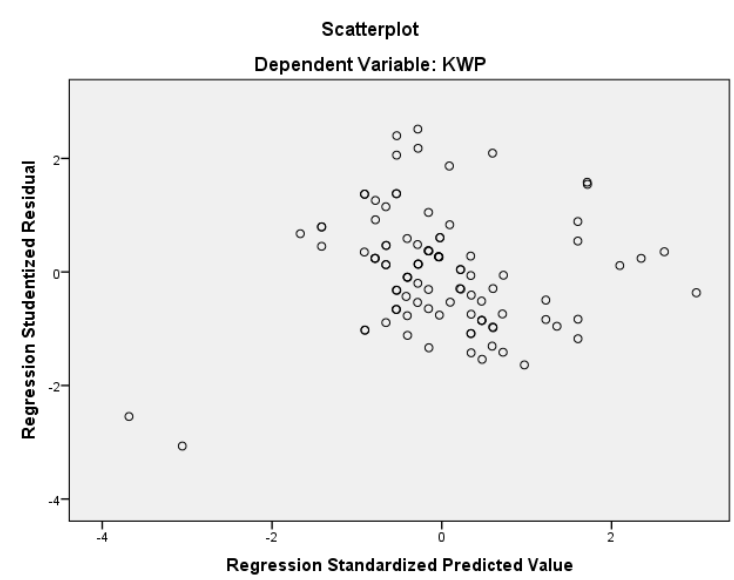

\section{Gambar 4.1}

Uji Heteroskedastisitas

Berdasarkan hasil uji heteroskedastisitas Gambar 4.1 menunjukan titik - titik menyebar secara acak serta tersebar. Hal ini menunjukan bahwa pada model regresi tersebut tidak terjadi heteroskedastisitas, sehingga model regresi layak dipakai untuk memprediksi Persepsi Wajib Pajak terhadap Kepatuhan Wajib Pajak dengan Preferensi Risiko sebagai Variabel Moderating.

\subsection{Uji Hipotesis}

Penelitian ini diuji dengan menggunakan analisis regresi linier berganda. Yang menghasilkan data sebagai berikut :

Tabel 4.11

Koefisien Regresi

\begin{tabular}{|c|c|c|}
\hline Model & Unstandardized Coefficients & $\begin{array}{c}\text { Standardized } \\
\text { Coefficients }\end{array}$ \\
\hline
\end{tabular}




\begin{tabular}{|l|r|r|r|}
\hline & B & Std. Error & Beta \\
\hline (Constant) & 8,647 & 3,985 &, 658 \\
\hline PWP &, 322 &, 038 &, 003 \\
\hline PR &, 004 &, 089 & \\
\hline
\end{tabular}

Persamaan regresi yang terjadi adalah : $\mathrm{KWP}=8,647+0,322 \mathrm{X} 1+0,004 \mathrm{X} 2+3,985$

\subsubsection{Uji Parsial $t$}

Tabel 4.10

Uji t

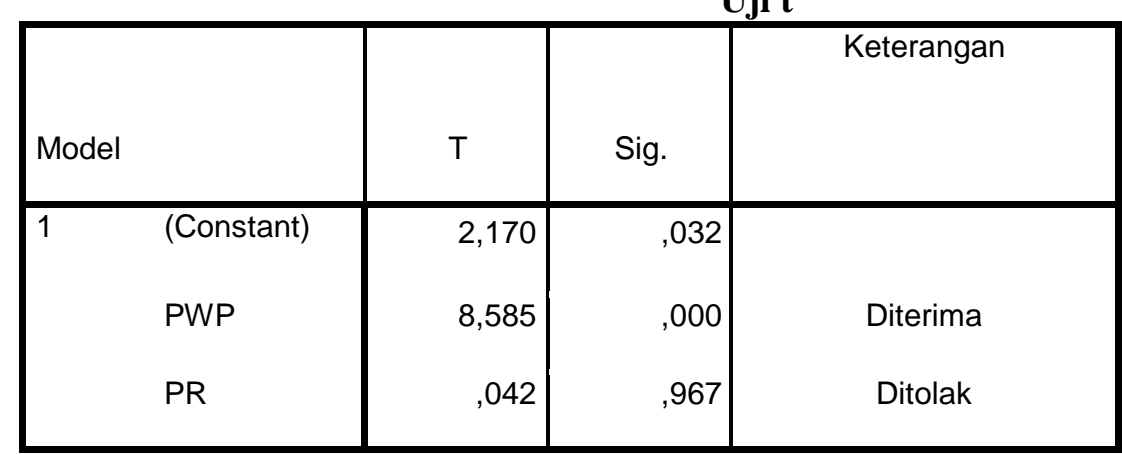

Dependent Variable: KWP

H1 : Persepsi Wajib Pajak mempunyai tingkat signifikan 0,000 dengan nilai t hitung 8,585 dan ttabel 1,985. Tingkat signifikan yang dimiliki variabel Persepsi Wajib Pajak sebesar $0,000<$ 0,05 dan thitung $8,124>1,985$ ttabel. Jadi dengan tingkat signifikan tersebut dapat ditarik kesimpulan bahwa Persepsi Wajib Pajak berpengaruh secara positif dan signifikan terhadap Kepatuhan Wajib Pajak. Sehingga Hipotesis 1 (H1) Diterima.

H2 : Pengaruh Preferensi Risiko terhadap Kepatuhan Wajib Pajak hasil pengujian pada tabel 4.11 tingkat signifikan 0,967 dengan nilai thitung $(0,042)$ dan ttabel $(1,985)$. Dengan tingkat signifikan yang dimiliki variabel moderating $0,967>0,05$ dan nilai thitung $(0,42)<(1,985)$ ttabel, maka Hipotesis 2 (H2) Ditolak.

\subsubsection{Uji Koefisien Determinasi}

Tabel 4.12

Uji Koefisien Determinasi

\begin{tabular}{|c|c|c|c|c|}
\hline \multicolumn{5}{|c|}{ Ujı Koetisien Determinasi } \\
\hline Model & $\mathrm{R}$ & R Square & Adjusted R Square & $\begin{array}{l}\text { Std. Error of the } \\
\text { Estimate }\end{array}$ \\
\hline 1 &, $658^{\mathrm{a}}$ & ,433 & ,421 & 2,96302 \\
\hline
\end{tabular}

Predictors : PR, PWP

Berdasarkan tabel 4.12 diatas dapat dilihat bahwa nilai koefisien Adjusted $R$ square sebesar $42,1 \%$. Koefisien determinasi menunjukan bahwa 42,2\% Kepatuahan Wajib Pajak dipengaruhi oleh Persepsi Wajib Pajak dan Preferensi Risiko. Sedangkan sisanya ( $100 \%$ $42,1 \%=57,9 \%$ ) dijelaskan oleh faktor lain yang tidak diteliti dalam penelitian ini. 


\subsubsection{Uji Simultan F (Anova)}

Tabel 4.13

Uji F (Annova)

\begin{tabular}{|l|r|r|r|r|r|}
\hline Model & \multicolumn{1}{|c|}{ Sum of Squares } & \multicolumn{1}{c|}{ df } & Mean Square & F & Sig. \\
\hline Regression & 649,778 & 2 & 324,889 & 37,005 &, $000^{\mathrm{D}}$ \\
\hline Residual & 851,612 & 97 & 8,780 & & \\
\hline Total & 1501,390 & 99 & & & \\
\hline
\end{tabular}

Dependent Variabel : KWP

Predictors : PR, PWP

Berdasarkan tabel 4.13 dapat diketahui dengan rumus $\mathrm{df}=\mathrm{n}-\mathrm{k}-1(\mathrm{df}=100-3)=97$ dan $\mathrm{df}=\mathrm{k}-1(\mathrm{df}=3-1)=2$. Dan nilai Fhitung 37,005 > 3,09 Ftabel. Dengan nilai signifikan $0,000<0,05$, Persepsi Wajib Pajak dan Preferensi Risiko secara bersama - sama berpengaruh secara signifikan terhadap Kepatuhan Wajib Pajak.

\subsubsection{Diskusi Hasil dan Pembahasan}

\subsubsection{Persepsi Wajib Pajak berpengaruh terhadap Kepatuhan Wajib Pajak}

Persepsi Wajib Pajak berpengaruh signifikan terhadap Kepatuhan Wajib Pajak Orang Pribadi dengan tingkat signifikan sebesar $0,000<0,05$ dan thitung 8,124 > ttabel 1,985 dengan menunjukan arah positif. Aryobimo (2014) mengatakan bahwa, "Kualitas pelayanan fiskus yang baik dan jujur mampu mempengaruhi persepsi Wajib Pajak, sehingga akan mampu meningkatkan kepatuhan Wajib Pajak." Hasil Penelitian ini sejalan dengan penelitian yang di lakukan oleh Mangumban, (2015), yang menyatakan bahwa Persepsi Wajib Pajak berpengaruh terhadap Kepatuhan Wajib Pajak. Dan dalam penelitian ini dapat disimpulkan bahwa pelayanan fiskus di KPP Pratama Jakarta Kebayoran Baru Tiga terhadap Wajib Pajak sudah berjalan dengan baik sehingga Persepsi Wajib Pajak di Wilayah Jakarta Kebayoran Baru Tiga menjadi baik pula. Hal ini juga bisa dilihat dari kuesioner yang disebar, rata - rata Wajib Pajak memberikan penilain setuju pada pertanyaan tersebut.

\subsubsection{Preferensi Risiko berpengaruh terhadap Kepatuhan Wajib Pajak}

Tingkat signifikan 0,967 dengan nilai thitung $(0,042)$ dan ttabel $(1,985)$. Dengan tingkat signifikan yang dimiliki variabel $0,967>0,05$ dan nilai thitung $(0,42)<(1,985)$ ttabel, maka Hipotesis ditolak. Preferensi Risiko tidak berpengaruh terhadap Kepatuhan Wajib Pajak. Preferensi Risiko yang tidak berpengaruh terhadap Kepatuhan Wajib Pajak dapat dikarenakan preferensi resiko yang ada adalah resiko dari pribadi wajib pajak yang berkaitan dengan risiko kesehatan, risiko keselamatan, dan risiko pekerjaan, tidak akan mampu mengubah persepsi Wajib Pajak terhadap kualitas pelayanan, dimana tinggi rendahnya persepsi Wajib Pajak terhadap kualitas pelayanan fiskus tergantung pada baik buruknya pelayanan yang diberikan oleh KPP Pratama Jakarta Kebayoran Baru Tiga. Hasil penelitian ini didukung oleh penelitian yang dilakukan oleh Monika, (2013), maupun Jamiati, (2015) yang menunjukkan bahwa preferensi risiko tidak berpengaruh kepatuhan Wajib Pajak.

\section{SIMPULAN}

Dari diskusi hasil dan pembahasan mengenai Preferensi Risiko Sebagai Variabel Moderating Dalam Pengaruh Persepsi Wajib Pajak Terhadap Kepatuhan Wajib Pajak dapat disimpukan sebagai berikut : 
1. Persepsi Wajib Pajak berpengaruh positif signifikan terhadap Kepatuhan Wajib Pajak. Dan dalam penelitian ini dapat disimpulkan bahwa pelayanan fiskus di KPP Jakarta Kebayoran Baru Tiga terhadap Wajib Pajak sudah sangat baik sehingga mampu mempengaruhi Persepsi Wajib Pajak di Wilayah KPP Pratama Jakarta Kebayoran Baru Tiga. Hal ini juga dapat dilihat dari kuesioner yang disebar, rata - rata Wajib Pajak memberikan penilaian setuju terhadap butir pertanyaan tersebut.

2. Preferensi tidak berpengaruh terhadap Kepatuhan Wajib Pajak. Tinggi rendahnya preferensi risiko ternyata tidak mempengaruhi Wajib Pajak untuk tetap patuh. Hal ini dapat dikaitkan dengan kualitas pelayanan yang diberikan oleh fiskus. Preferensi risiko yang tidak berpengaruh terhadap kepatuhan Wajib Pajak dapat dikarenakan preferensi resiko yang ada adalah resiko dari pribadi Wajib Pajak yang berkaitan dengan risiko kesehatan, risiko keselamatan, dan risiko pekerjaan, tidak akan mampu mengubah persepsi Wajib Pajak terhadap kualitas pelayanan, dimana tinggi rendahnya persepsi Wajib Pajak terhadap kualitas pelayanan fiskus tergantung pada baik buruknya pelayanan yang diberikan oleh KPP Pratama Jakarta Kebayoran Baru Tiga

\section{KETERBATASAN}

1. Peneliti hanya menggunakan metode survey dengan kuesioner, tanpa terlibat secara langsung dalam wawancara dengan responden, sehingga informasi yang didapatkan mengandung unsur bias.

2. Data penelitian yang berasal dari persepsi responden yang disampaikan secara tertulis dengan bentuk instrument kuesioner mungkin dapat mempengaruhi validitas hasil.

3. Persepsi responden memiliki kemungkinan jawaban yang kurang jujur, sehingga tidak menghasilkan jawaban yang diinginkan dalam penelitian ini.

4. Dalam penelitian ini, penulis hanya menggunakan tiga variabel saja yaitu Persepsi Wajib Pajak, Preferensi Risiko yang digunakan untuk memprediksi Kepatuhan Wajib Pajak.

\section{SARAN}

1. Berdasarkan hasil penelitian menyatakkan bahwa Persepsi Wajib Pajak berpangaruh positif signifikan terhadap Kepatuhan Wajib Pajak. Artinya kualitas fiskus yang diberikan kepada Wajib Pajak di KPP Pratama Jakarta Kebayoran Baru Tiga cukup baik dan jujur, sehingga Persepsi Wajib Pajak berubah mengenai fiskus sehingga meningkatkan Kepatuhan Wajib Pajak. Akan tetapi untuk tetap mempertahankan Tingkat Kepatuhan Wajib Pajak di KPP Pratama Jakarta Kebayoran Baru Tiga dari tahun ketahun, sebaiknya kantor pelayanan pajak meningkatkan lagi kualitas yang diberikan untuk kedepannya.

2. Berdasarkan hasil penelitian menyatakan bahwa Preferensi Risiko sebagai variabel independent tidak berpengaruh terhadap hubungan antara Persepsi Wajib Pajak dengan Kepatuhan Wajib Pajak. Dengan demikian, untuk peneliti selanjutnya bisa menggunakan variabel preferensi risiko tersebut sebagai variabel moderating atau intervening.

3. Untuk Penelitian selanjutnya diharapkan mampu menambah objek penelitian, tidak hanya pada KPP Pratama Jakarta Kebayoran Baru Tiga, sehingga bisa didapatkan sampel yang lebih baik. Penilaian Kepatuhan Wajib Pajak akan lebih objektif apabila ketepatan tanggal pembayaran juga dijadikan pengukuran data dalam kuesioner.

4. Selain menggunakan keusioner secara tertulis, bisa ditambahkan wawancara atau interview, penelitian selanjutnya diharapkan melaksanakan penelitian dengan responden yang lebih luas agar penelitian dapat digunakan secara universal.

\section{DAFTAR PUSTAKA}

Adiasa, Nirawan. 2013. "Pengaruh pemaham peraturan perpajakan terhadap kepatuhan wajib pajak dengan variabel moderating preferensi risiko”. Universitas Negeri Semarang. 
Arum, Harjanti Puspa. 2012. "Pengaruh Kesadaran Wajib Pajak, Pelayanan Fiskus dan Sanksi Pajak, Terhadap Kepatuhan Wajib Pajak Orang Pribadi yang Melakukan Pekerjaan Bebas". Universitas Diponegoro.

Aryobimo, Putut tri. 2012. "Pengaruh Persespi Wajib Pajak tentang Kualitas pelayanan Fiskus, Terhadap Kepatuahan Wajib Pajak dengan Kondisi Keuangan Wajib Pajakdan Preferensi Risiko Sebagai Variabel Moderating”. Universitas Diponegoro.Semarang”.

Dewi, Mira Riangga. 2011. "Persepsi Wajib Pajak Atas Pengenaan Pajak Penghasilan : Anteseden dan Konsekuensinya (Kajian Empiris pada Wajib Pajak Orang Pribadi Yang Memiliki Usaha di Kota Kudus) ".

Ismawati. 2017. "Pengaruh pemahaman peraturan perpajakan, kualitas pelayanan fiskus, sanksi perpajaka, dan tax amnesty terhadap kepatuhan wajib pajak dengan preferensi risiko sebagai variabel moderasi (studi kasus pada KPP Pratama Kota Kudus".

James O. Olabede, 2011. "Pengaruh persepsi tentang kualitas pelayanan fiskus terhadap kepatuhan wajib pajak dengan di moderasi oleh kondisi keuangan wajib pajak dan preferensi risiko yang dihadapi. Objek penelitian ini di negara berkembang Nigeria".

Jamiati. 2015. "Pengaruh Persepsi Wajib Pajak tentang Kualitas Pelayanan Fiskus, Pelaksanan Sensus, Pelayanan sensus Pajak Nasional, Sosialisasi Perpajakan, dan Sanksi Pajak Terhadap Kepatuhan Wajib Pajak dengan Kondisi Keuangan Wajib Pajak dan Preferensi Risiko Sebagai Variabel Moderating”.

Jatmiko, Agus Nugroho. (2006). "Pelaksanaan Sanksi Denda, Pelayanan Fiskus dan Kesadaran PErpajakan terhadap Kepatuhan Wajib Pajak." (Studi Empiris terhadap Wajib Pajak Orang Pribadi di Kota Semarang). Tesis. Fakultas Ekonomi Universitas Diponegoro. Semarang.

Mangumban, Brilyan Tiara. "Persepsi Wajib Pajak Terhadap Kepatuhan Wajib Pajak PPN". Makasar.

Muliari dan Setiawan, 2009. "Pengaruh Persepsi, Sanksi Perpajakan dan Kesadaran Wajib Pajak pada Kepatuhan Pelaporan Wajib Pajak Orang Pribadi di Kpp Denpasar Timur”. Skripsi. Fakultas Ekonomi Universitas Udaya.

Olabede, James O. 2011. "Pengaruh persepsi tentang kualitas pelayanan fiskus terhadap kepatuhan wajib pajak di Nigeria dengan kondisi keuangan dan preferensi resiko sebagai variabel moderating". Diakses dalam penelitian Aryobimo. 2012.

Pertiwi, Vivi Indah. 2015. "Pengaruh Penagihan Pajak Pasif, penagihan pajak Aktif, Terhadap Penyelesiaan Tunggakan Pajak dengan Gijzeling Sebagai variabel Moderating". Universitas Pamulang.

Priyanto, Duwi. 2017. "Panduan Praktis Olah Data SPSS Menggunakan SPSS.” Ed. I. Yogyakarta : Andi.

Sugiyono, Prof, Dr. 2012. "Metode Penelitian Kuantitatif Kualitatif".

Syamsudin, Marta. 2014. "Pengaruh Persepsi Wajib Pajak Tentang Kualitas pelayanan Fiskus Terhadap Kepatuhan Wajib Pajak Dengan Kondisi Keuangan Wajib Pajak Dan Preferensi Risiko Sebagai Variabel moderating”. (Studi Empiris Terhadap Wajib Pajak Orang Pribadi Di Kota Semarang). Fakultas Ekonomika dan Bisnis Universitas Stikubank.

Torgler, B. 2003. "Tax Morale : Theory and Analysis of Tax Compliance. Unpublished doctoral dissertion, University of Zurich, Switzerland".

Utomo. 2015. "Pengaruh kesadaran wajib pajak, pengetahuan perpajakan dan sanksi terhadap kepatuhan wajib pajak”. PT Grasindo, Anggota Ikapi. Jakarta.

Wahyudi. $\quad$ 2015. "Pengaruh Persepsi Wajib Pajak tentang Kualitas Pelayanan Fiskus Terhadap Kepatuhan Wajib Pajak dengan Kondisi Keuangan Wajib Pajak dan Preferensi Risisko Sebagai Varaibel Moderating”.

https://goo.gl/images/LSu3DV. Diakses 23 Mei 208.

www.pajak.go.id. Diakses 17 November 2017

https://www.online-pajak.com 